\title{
Colloidal carbon particles as a new label for rapid immunochemical test methods: Quantitative computer image analysis of results
}

\author{
A. van Amerongen a , J.H. Wichers ${ }^{\text {b }}$, L.B.J.M. Berendsen ${ }^{\text {a }}$, \\ A.J.M. Timmermans ${ }^{\text {a }}$, G.D. Keizer ${ }^{\text {b }}$, A.W.J. van Doorn ${ }^{\text {b }}$, \\ A. Bantjes ${ }^{\text {c }}$ and W.M.J. van Gelder ${ }^{a}$ \\ ${ }^{a}$ Agrotechnological Research Institute ATO-DLO, Wageningen, The Netherlands \\ ${ }^{b}$ HBT Holland Biotechnology, Leiden, The Netherlands \\ ' Department of Chemical Technology, Technical University Twente, Enschede, The Netherlands
}

(Received 23 October 1992; revision accepted 27 January 1993)

Summary

Colloidal carbon particles can serve as label in sol particle immunoassays. The universal applicability of these particles in qualitative and (semi)quantitative immunoassays has been demonstrated. Sol particle and/or dipstick immunoassays, not yet optimized in terms of sensitivity, are discussed.

The colloidal label has been used successfully in a mouse immunoglobulin isotyping kit. Human serum albumin spotted onto nitrocellulose in a concentration range of 7.8 to $1000 \mathrm{ng}$ could be detected using anti-albumin antibody adsorbed onto colloidal carbon particles. It was also possible to perform a competitive assay with this conjugate for a concentration range of free human serum albumin varying from 0.25 to $6.75 \mu \mathrm{g}$. The Kunitz-type trypsin inhibitor from soybean was determined by a colloidal carbon based immunoassay in a range of 2.5 to $160 \mathrm{ng}$. In this assay, free and colloidal carbon-bound inhibitor competed for binding specific antibodies spotted onto a nitrocellulose membrane.

An image- and data-processing procedure has been developed that enables a rapid and simple quantification of colloidal carbon sol particle immunoassays. The average grey level of a spot is taken as a measure for quantitative purposes. This

Correspondence to: A. van Amerongen, Agrotechnological Research Institute ATO-DLO, P.O. Box 17, 6700 AA Wageningen, The Netherlands. 
so-called Sol-particle Image Processed ImmunoAssay (SIPIA) procedure is equally well applicable to assays using other colloidal particles.

Colloid; Quantification; Sol particle immunoassay; Computer image analysis; Human serum albumin; Kunitz-type trypsin inhibitor

\section{Introduction}

For assessing safety and quality characteristics of plant, food and feed, and for monitoring processing of biological materials, a growing need exists for rapid, simple and cheap tests. Also for human and veterinary diagnostics, rapid tests are becoming increasingly important. The application of immunochemical test methods has several advantages, especially simplicity and speed (Gosling, 1990). Considering these requirements, sol particle immunoassays (SPIA's) are very suited for detection of a variety of components. Gold, latex and dye colloidal particles, traditionally used for SPIA's, sometimes suffer from disadvantages such as high costs, difficulty of preparation and low stability.

To overcome these drawbacks and to broaden the applications of SPIA's, we aimed at developing a colloidal suspension that should be cheap, easy to prepare, highly stable and that had to show excellent labelling potency characteristics. In addition, it should be possible to adsorb ligand onto the colloidal particle, resulting in a conjugate that was colloid-chemically stable, had unaltered physical properties and an immunochemical activity comparable with the free ligand. Finally, detection of the conjugate using simple assay-formats was a prerequisite.

Among several non-metallic colloidal suspensions investigated, such as selenium and silicium sols (Van Doorn et al., 1988; Wichers et al., 1989a,b), colloidal carbon particles turned out to be well suited to serve as label in sol particle immunoassays.

In this study, results achieved with these colloidal carbon particles will be discussed. In addition to the introduction of this new label, the application of computer image analysis, as a means of quantifying SPIA's, will be presented.

\section{Materials and Methods}

Preparation of colloidal carbon suspension

Colloidal carbon suspensions were prepared as described in the European Patent Application EP.A 88202597.6 by Van Doorn et al. (1988).

\section{Preparation of colloidal carbon particles-protein conjugates}

The choice of buffer and/or $\mathrm{pH}$ for the preparation of colloidal particle-protein conjugates largely depends on the $\mathrm{pI}$ of the protein to be adsorbed. As a rule the $\mathrm{pH}$ of the buffer solution must be $0.5-1.0 \mathrm{pH}$-unit higher than the $\mathrm{pI}$ of the protein. The ionic strength of the buffer should be kept at or below $5 \mathrm{mM}$. 
Procedure: Protein to be adsorbed was dissolved in an appropriate buffer and incubated with a $0.2 \%(\mathrm{w} / \mathrm{v})$ colloidal carbon suspension in the same buffer to a final protein concentration between 0.5 and $1.5 \mathrm{mg} \mathrm{ml}^{-1}$. The suspension was gently stirred for $3 \mathrm{~h}$ at room temperature. For assessing whether adsorption was successful, a flocculation test was carried out as follows. (A) To $1 \mathrm{ml}$ of the conjugate, $200 \mu \mathrm{l}$ distilled water was added. After mixing the colloidal suspension had to remain stable. (B) $200 \mu \mathrm{l} 10 \%$ (w/v) NaCl was mixed with another $1 \mathrm{ml}$ of the suspension. This suspension had to remain stable as well. If flocculation of the colloidal suspension did occur, another buffer $(\mathrm{pH}$, ionic strength) was tested and/or the amount of protein was raised.

A stable conjugate was washed three times in a solution containing $5 \mathrm{mM}$ Tris- $\mathrm{HCl}, 1 \%(\mathrm{w} / \mathrm{v}) \mathrm{BSA}$ and $0.02 \%(\mathrm{w} / \mathrm{v}) \mathrm{NaN}_{3}$ at $\mathrm{pH} 8.5$ and after each washing step centrifuged for $30 \mathrm{~min}$ at $13000 \mathrm{~g}$. The final pellet was resuspended in buffer to the original volume. The conjugate was stored at $4^{\circ} \mathrm{C}$.

\section{Test method for mouse immunoglobulin isotyping}

A method for the isotyping of mouse immunoglobulins has been developed using a colloidal carbon suspension. A rat anti-mouse kappa (or lambda) monoclonal antibody (Euroclone, Amsterdam, The Netherlands) was coupled onto colloidal carbon particles in $2.5 \mathrm{mM}$ Tris- $\mathrm{HCl}, \mathrm{pH} 8.5$ according to the procedure described above.

Volumes of $500 \mu \mathrm{l}$ hybridoma supernatant, containing amounts of monoclonal antibody varying from 5 to $50 \mu \mathrm{g}$ were mixed each with $250 \mu \mathrm{l}$ distilled water and $250 \mu 1 \mathrm{MIB}$ (i.e., $20 \mathrm{mM}$ Tris- $\mathrm{HCl}, 600 \mathrm{mM} \mathrm{NaCl}, 1 \%$ (w/v) BSA, $0.2 \%$ (v/v) Tween-20, $\left.0.02 \%(\mathrm{w} / \mathrm{v}) \mathrm{NaN}_{3}, \mathrm{pH} 8.5\right)$ and incubated for 15-30 min with a nitrocellulose test-strip onto which rat anti-mouse immunoglobulin isotype-specific monoclonal antibodies were spotted (Holland Biotechnology, Leiden, The Netherlands, Mouse Isotyping Kit, No. L10-10/L10-20). After a short wash-step with running distilled water, the strip was incubated in $250 \mu \mathrm{l} \mathrm{MIB}, 700 \mu \mathrm{l}$ distilled water and $50 \mu \mathrm{l}$ of the colloidal carbon-antibody conjugate. The isotype of the monoclonal antibodies was simply determined by reading the black-colored spots which appeared after a few minutes incubation. Maximum color intensity was reached in most cases after $30 \mathrm{~min}$. Color development was stopped by removing the conjugate suspension and rinsing the strip in distilled water for $10 \mathrm{~s}$.

\section{SPIA for human serum albumin}

Human serum albumin (HSA) was detected by a SPIA test format. HSA (Boehringer, Mannheim, Germany) was spotted onto nitrocellulose strips (Schleicher and Schuell, Dassel, Germany, BA-85/23, pore diameter $0.45 \mu \mathrm{m}$ ) in eight serial dilutions (1000 to $7.8 \mathrm{ng}$ ) in $10 \mathrm{mM}$ PBS, pH 7.4. Dried strips were blocked in $10 \mathrm{mM}$ PBS, $2 \%(\mathrm{w} / \mathrm{v}) \mathrm{BSA}, 0.02 \%(\mathrm{w} / \mathrm{v}) \mathrm{NaN}_{3}, \mathrm{pH} 7.4$ for $90 \mathrm{~min}$ at $37^{\circ} \mathrm{C}$. Strips were plastic-backed with Serocluster Plate-sealers (Costar, Cambridge, UK). A monoclonal antibody directed against HSA (Clone M II, Boehringer, Mannheim, Germany) was coupled onto colloidal carbon particles in $2.5 \mathrm{mM}$ Tris- $\mathrm{HCl}, \mathrm{pH} 8$ as described above. The strips were placed in 3-ml plastic tubes 
and were incubated ( $30 \mathrm{~min}$ to $16 \mathrm{~h}$ ) in a suspension containing $250 \mu \mathrm{l} \mathrm{MIB}, 700$ $\mu \mathrm{l}$ distilled water and $50 \mu \mathrm{l}$ of the colloidal carbon-monoclonal antibody conjugate. Results were evaluated by visual examination and by computer image analysis (see hereafter).

In a competitive test format, nitrocellulose strips, onto which $62 \mathrm{ng}$ of HSA had been spotted, were incubated each in the same buffer containing increasing amounts of free HSA $(0.25$ to $6.75 \mu \mathrm{g})$ mixed with the colloidal carbon-anti-HSA monoclonal antibody conjugate in a total volume of $1 \mathrm{ml}$, containing $250 \mu \mathrm{l}$ MIB. Inhibition was assessed visually and by computer image analysis (see hereafter).

\section{SPIA for soybean Kunitz-type trypsin inhibitor}

Soybean Kunitz-type trypsin inhibitor (KTI; Sigma, St. Louis, MS, USA) was purified by Fast Protein Liquid Chromatography (Pharmacia, Uppsala, Sweden) on a Mono $\mathrm{Q}$ anion-exchange column (result not shown). The purified protein (1.6 $\mathrm{mg}$ ) was adsorbed onto a $0.2 \%$ colloidal carbon suspension in a total volume of 1 $\mathrm{ml} 5 \mathrm{mM}$ MES-buffer, $\mathrm{pH} 5.0$ during an overnight incubation. The conjugate was washed three times as described above and the final pellet was resuspended in 10 $\mathrm{mM}$ MES-buffer, $\mathrm{pH} 6.0$ and used in a chromatographic dipstick device. On nitrocellulose strips (Schleicher and Schuell, Dassel, Germany, type AE-99, pore diameter $8 \mu \mathrm{m}$ ), cut in $3 \times 0.5 \mathrm{~cm}$ strips, affinity-purified rabbit polyclonal antibodies $(1 \mu \mathrm{l}$ containing $2 \mu \mathrm{g}$ of affinity-purified IgG in phosphate buffered saline, $\mathrm{pH}$ 7.4) was spotted. The dry strips were blocked and plastic-backed as described for the HSA strips. As a fluid drain, a piece $(5 \times 0.5 \mathrm{~cm})$ of buffer paper was sticked on top of the nitrocellulose strips. After pre-wetting the strips by chromatographing $10 \mu \mathrm{l} 10 \mathrm{mM}$ MES, $\mathrm{pH} 6.0,20 \mu \mathrm{l}$ of MES-buffer containing serial dilutions of KTI ( 0 to $160 \mathrm{ng}$ ) were run, followed by $20 \mu \mathrm{l}$ of MES-buffer. Finally, $25 \mu \mathrm{l}$ MES-buffer containing $5 \mu \mathrm{l}$ of the colloidal carbon-KTI conjugate was chromatographed, followed by $30 \mu \mathrm{l}$ of MES-buffer. Quantification of grey levels was by computer image analysis.

\section{Quantification of grey levels by computer image analysis}

Sol particle immunoassays are used to give visually estimated qualitative or semi-quantitative results. To convert these assays to a quantitative format, the applicability of computer image analysis was studied. Black/grey-colored spots were recorded with standardized settings with a video camera (iVC500, Sony), mounted on a microscope (Olympus SZ-CTV, $10 \times$ magnification) and illuminated by the Highlight 2000 system (Olympus). The video signals were sampled on a grid to a digital image with a spatial resolution of $512 \times 512$ picture elements (pixels). Grey values of pixels varied from 0 (black) to 255 (white). The digital images were processed by a Quantimet 520 system (Cambridge Instruments, UK). Standard settings included a frame that recorded $4000-5000$ pixels per spot. For every spot the following parameters were calculated: area, sum, mean, standard deviation, maximum, minimum, medium, mode and pixel grey-level distribution. To align results with traditional immunochemical assays (i.e., higher assay-values when higher amounts of antibody are bound), values were expressed as 255 minus the 
average grey levels per spot (grey-level scaling). This quantitative assay-format of SPIA's has been termed Sol-particle Image Processed ImmunoAssay (SIPIA).

\section{Results}

\section{Mouse immunoglobulin isotyping kit}

The speed and simplicity of determining the isotypes of mouse monoclonal immunoglobulins using colloidal carbon particles were evaluated for various hybridoma supernatants containing monoclonal antibodies with known isotypes (Fig. 1). The monoclonal antibodies were correctly identified by reading the black-colored spots for heavy and light chains. In these experiments, amounts of monoclonal antibodies varying from 5 to $50 \mu \mathrm{g} \mathrm{ml}^{-1}$ could be detected. Problems concerning aggregation, false-negative or -positive results, etc. were not observed.

\section{SPIA for human serum albumin}

Human serum albumin (HSA) was detected in a SPIA by colloidal carbon particles conjugated to a specific anti-HSA monoclonal antibody. In Fig. 2, a representative example of such an incubation ( $2 \mathrm{~h}$ ) is shown. An amount of $7.8 \mathrm{ng}$ HSA spotted onto a strip (spot 1) could be detected visually. In a recent experiment, the lowest amount visually detectable in this set-up appeared to be $2 \mathrm{ng}$

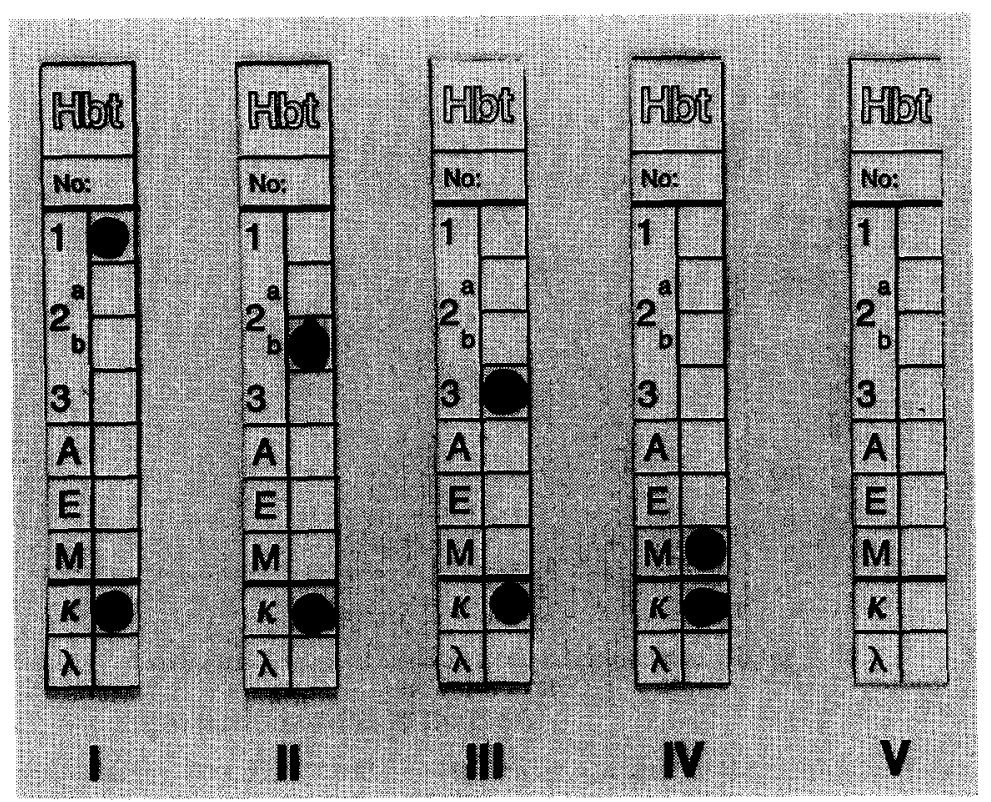

Fig. 1. Mouse immunoglobulin isotyping kit, based on a colloidal carbon-rat anti-mouse immunoglobulin conjugate as label. Strips I-V showing hybridoma supernatants $\left(5-50 \mu \mathrm{g} \mathrm{ml}^{-1}\right)$ with IgG1-kappa, IgG2b-kappa, IgG3-kappa, IgM and a non-producing hybridoma, respectively. 


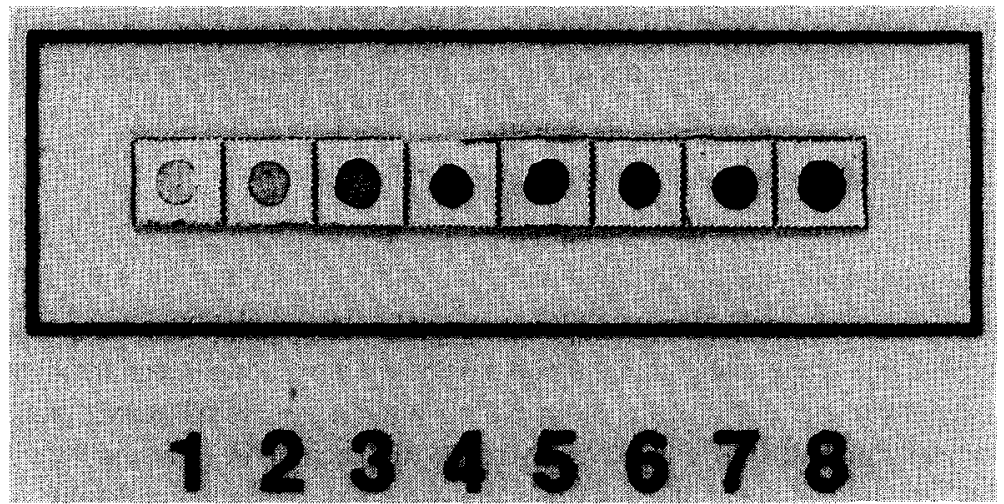

Fig. 2. SPIA for human serum albumin. Nitrocellulose spotted HSA (1, 7.8 ng; 2, $15.6 \mathrm{ng} ; 3,31.3 \mathrm{ng} ; 4$, $62.5 \mathrm{ng} ; 5,125 \mathrm{ng} ; 6,250 \mathrm{ng} ; 7,500 \mathrm{ng}$; and $8 ; 1000 \mathrm{ng}$ ) was labelled by anti-HSA monoclonal antibody adsorbed onto colloidal carbon particles.

(result not shown). The quantification of the average grey level of each spot was performed by computer image analysis. In Fig. 3, the grey level scaling is expressed as a function of the logarithm of the amount of HSA spotted. With the colloidal

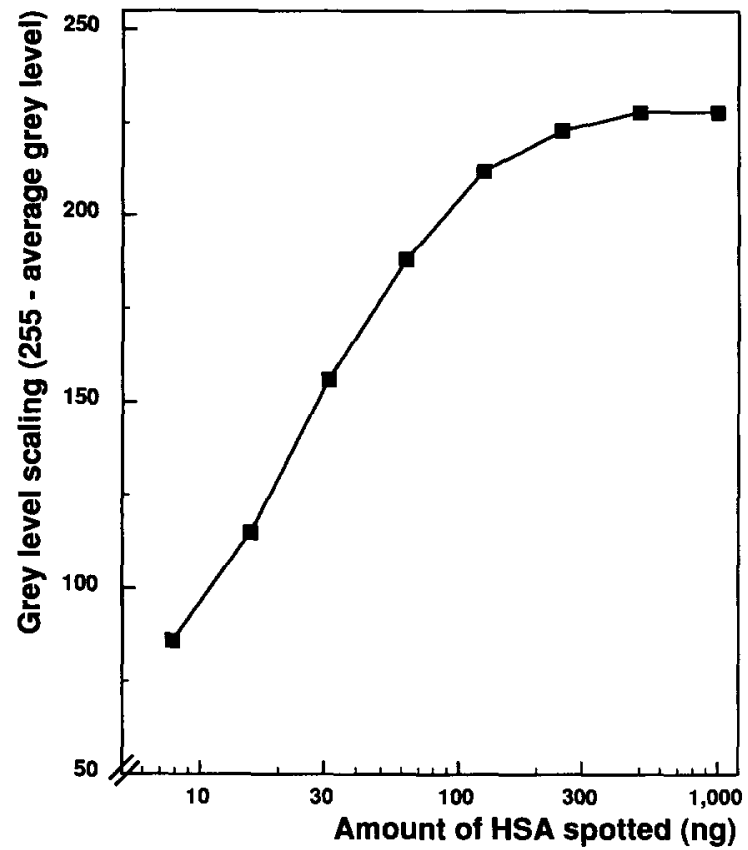

Fig. 3. Computer image analysis of a human serum albumin SPIA, based on colloidal carbon particles, onto which anti-HSA monoclonal antibody had been adsorbed. Nitrocellulose strips were spotted with increasing amounts of HSA (7.8-1000 ng) and incubated with the conjugate. Grey-level scaling (i.e., 255 minus the average of the grey levels of each spot) is expressed as a function of the logarithm of the amount of HSA spotted (ng). 


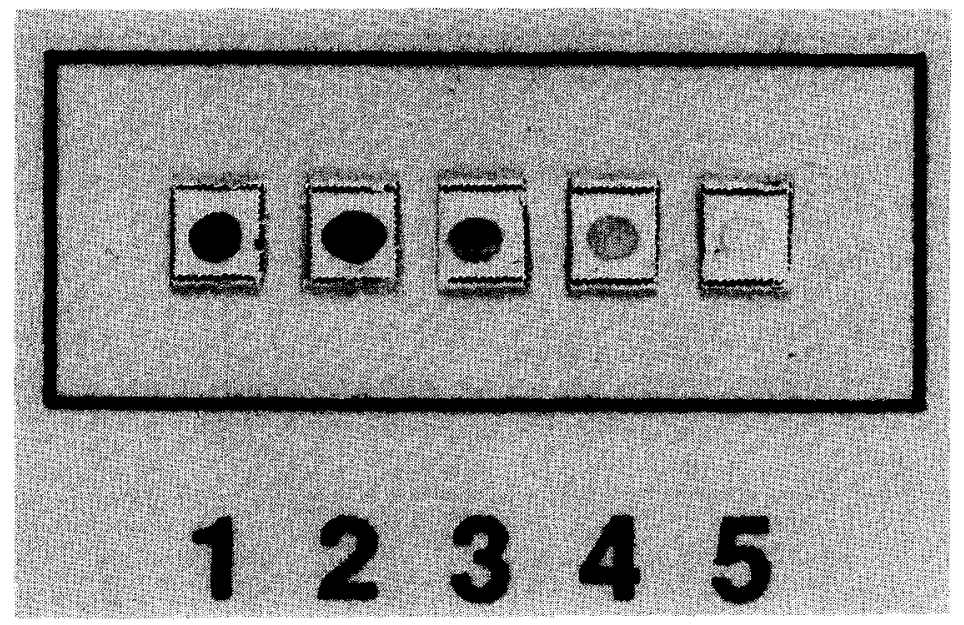

Fig. 4. SPIA for human serum albumin in a competitive test format. HSA, coated onto nitrocellulose (62 ng per spot), was incubated with a colloidal carbon-anti-HSA monoclonal antibody conjugate and increasing amounts of free HSA $(1,0 \mu \mathrm{g} ; 2,0.25 \mu \mathrm{g} ; 3,0.75 \mu \mathrm{g} ; 4,2.25 \mu \mathrm{g}$; and 5, $6.75 \mu \mathrm{g})$.

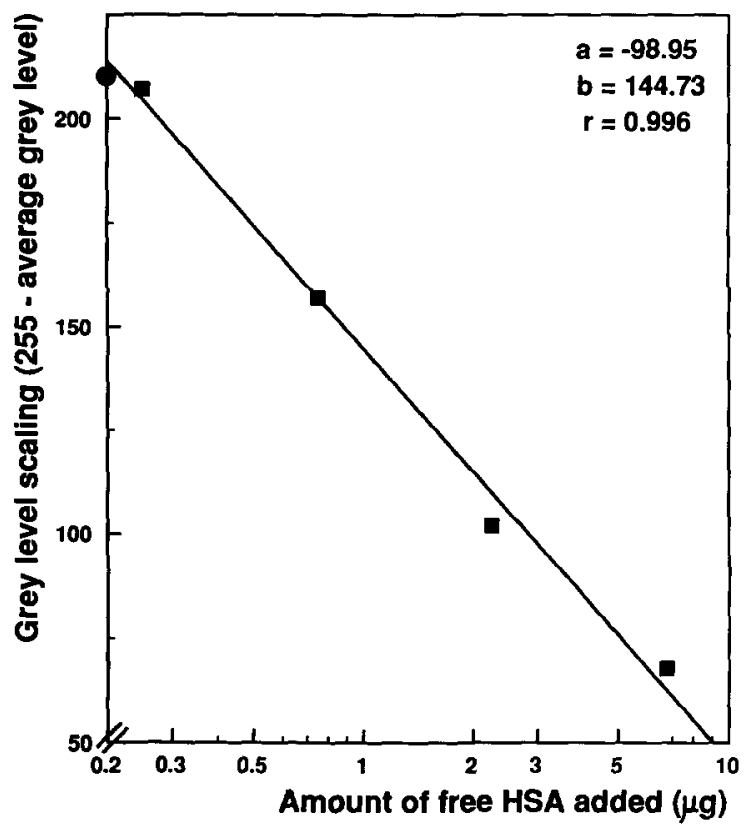

Fig. 5. Computer image analysis of a human serum albumin SPIA in a competitive test format, based on colloidal carbon particles, onto which anti-HSA monoclonal antibody had been adsorbed. Nitrocellulose strips were spotted with $62 \mathrm{ng} \mathrm{HSA}$ and incubated with the conjugate and increasing amounts of free HSA (0-6.75 $\mu \mathrm{g}$ ). Grey-level scaling (i.e., 255 minus the average of the grey levels of each spot) is expressed as a function of the logarithm of the amount of free HSA added. The blank (i.e., no free HSA added) is indicated by a solid circle on the $Y$-axis. Regression data, based on the squares, are shown in the figure. 


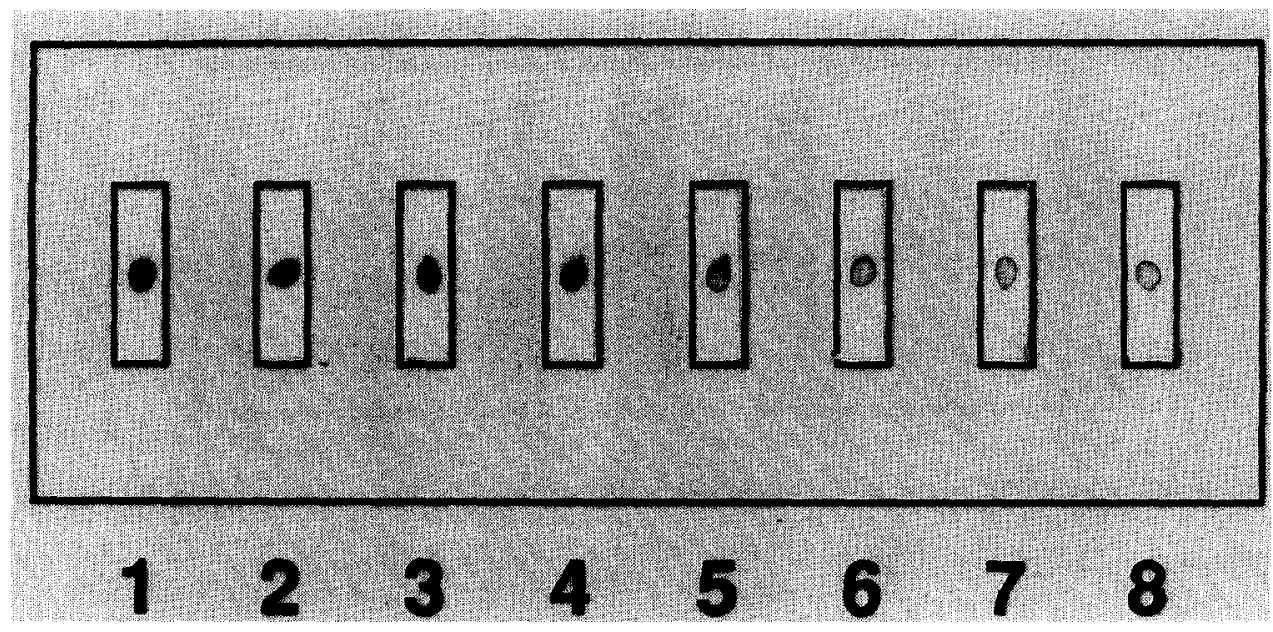

Fig. 6. SPIA for soybean Kunitz-type trypsin inhibitor in a competitive test format. Affinity-purified, rabbit polyclonal antibodies against KTI, coated onto nitrocellulose (approx. $2 \mu \mathrm{g}$ per spot), were incubated with a colloidal carbon-KTI conjugate and increasing amounts of free KTI (1, $0 \mathrm{ng} ; 2,2.5 \mathrm{ng}$; $3,5 \mathrm{ng} ; 4,10 \mathrm{ng} ; 5,20 \mathrm{ng} ; 6,40 \mathrm{ng} ; 7,80 \mathrm{ng}$; and 8, $160 \mathrm{ng}$ ).

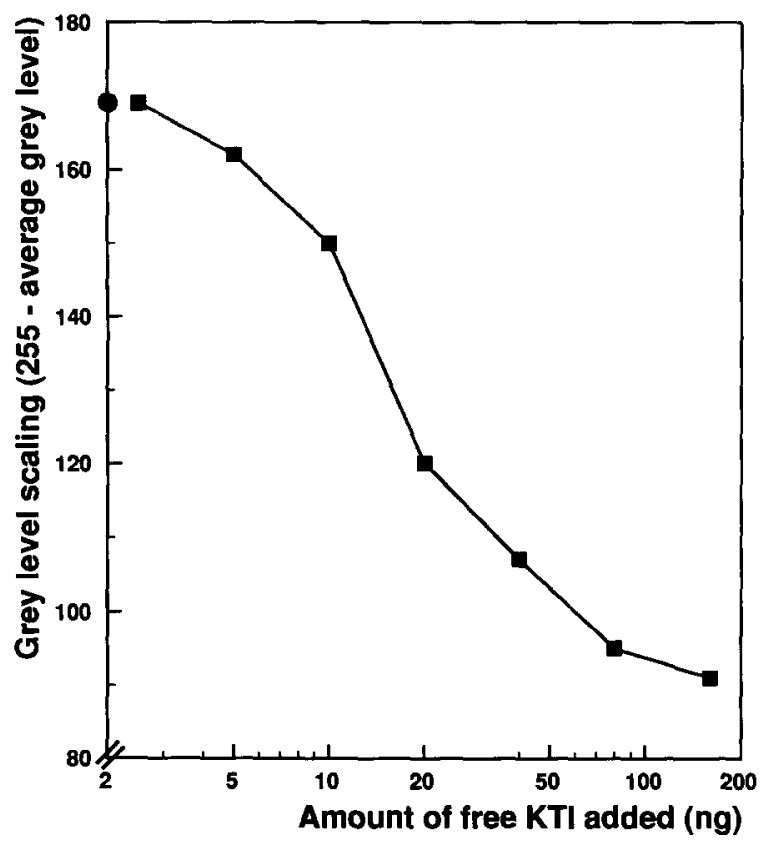

Fig. 7. Computer image analysis of a soybean Kunitz-type trypsin inhibitor SPIA in a competitive test format, based on colloidal carbon particles, onto which KTI had been adsorbed. Nitrocellulose strips were spotted with $2 \mu \mathrm{g}$ of affinity-purified, rabbit polyclonal antibodies against KTI and incubated with the conjugate and increasing amounts of free KTI (0-160 ng). Grey-level scaling (i.e., 255 minus the average of the grey levels of each spot) is expressed as a function of the logarithm of the amount of free KTI added. The blank (i.e., no free KTI added) is indicated by a solid circle on the $Y$-axis. 
carbon conjugate used, average grey levels of 7.8 to $500 \mathrm{ng}$ HSA spots could be discriminated. The shape of the curve plotted is similar to those obtained with comparable ELISA's.

In a competitive test format, shown in Fig. 4, free HSA was added to compete with nitrocellulose spotted albumin for binding to the colloidal carbon conjugate. In this experimental set-up, inhibiting amounts of free HSA were between 0.25 and $6.75 \mu \mathrm{g}$. Digitization of the results gave a good correlation $(r=0.996)$ between the grey-level scaling and the logarithm of the amount of free HSA added (Fig. 5).

\section{SPIA for soybean Kunitz-type trypsin inhibitor}

An initial attempt was made at developing a (semi-)quantitative assay for the determination of soybean Kunitz-type trypsin inhibitor. A teststrip of this competitive SPIA is shown in Fig. 6, whereas the relation between the amount of free KTI added and the average grey levels of the corresponding spots is depicted in Fig. 7. The results indicate that, by using this particular colloidal carbon particle-KTI conjugate, competing amounts of KTI between 2.5 and $160 \mathrm{ng}$ can be detected.

\section{Discussion}

In the present study, we describe the results of a first set of experiments performed with a colloidal carbon label. Several assay-formats have been chosen to proof the universal applicability of this label.

The colloidal carbon label appeared useful in the sol particle immunoassays studied. Considering the desired requirements for a new label, colloidal carbon has several advantageous characteristics and properties. In the first place, the label is very cheap and conjugates with proteins are easy to prepare. Secondly, the colloidal carbon label as well as the conjugates are very stable. Some conjugates were stored at $4^{\circ} \mathrm{C}$ for several months, others to one year, and still all gave similar results as in the initial experiments (results not shown). Finally, the black/grey spots on a white nitrocellulose background show a very good signal-noise ratio, as judged by visual examination and by computer image analysis. Based on these characteristics and properties, colloidal carbon suspensions can be well applied as a label in SPIA's, even when it is considered that the pilot experiments described in this study had not been optimized for sensitivity.

Further, we wondered whether the differences in grey-level intensities of the spots could be used to quantify SPIA's based on a colloidal carbon label. To this end, several possibilities exist to measure intensities of colored spots. Among these, laser densitometry has been widely used (Ungar and Nash, 1986; Palfreyman et al., 1988; Hogan et al., 1989; Stemerman et al., 1989). We studied the usefulness of computer image analysis to quantify colloidal carbon spots. The possibilities of this scanning technique, based on its adaptability and flexibility, have been shown in many areas. Applications include the quantification of agglutination (Prather et al., 1986), crossed immunoelectrophoretic patterns (Sondergaard et al., 1987) and immunohistochemical images to demonstrate particular antigens (Salgaller et al., 
1990; McClelland et al., 1991). In these cases, a stain (in the visual or fluorescent range) was used for quantification purposes, whereas in our case the colloidal particle itself was used to this end. In an experimental setup, carbon spots were magnified by microscopy, recorded by a video camera and the results were digitally processed. Standard settings were chosen such that the recording of one spot was covered by on average 4000 pixels. The average of the grey levels per spot was chosen as a measure for grey intensity. This will quench irregularities as a consequence of incubation set-up, or chromatographic direction. As shown in Fig. 3 , there is a strong relation between grey-level scaling (i.e., 255 minus the average grey level) and the logarithm of the amount of HSA spotted that is at least valid in a two orders of magnitude range. A test format of this HSA-SPIA with competitive, free HSA gave a high correlation $(r=0.996)$ between grey-level scaling and the logarithm of the amount of free HSA added (Fig. 5). Similar results were obtained for a competitive SPIA specific for a trypsin inhibitor (Fig. 7), although the polyclonal antibodies in this case did not allow a broad grey-level range (i.e., grey-level scaling between 90 and 170). In this respect, it has to be mentioned that the protein spotting onto nitrocellulose for all experiments was done by hand and that these preliminary studies were not optimized in terms of sensitivity.

Computer image analysis of carbon spots is possible and combines a rapid immunochemical test method with a technique of fast data-recording and -processing. The shape of curves obtained in the experiments described in this study is comparable with those of traditional immunochemical assays. The adaptability and flexibility of the technique guarantees it to be easy to use, since it can be automatized to a high degree. In terms of test formats, it is very flexible since soft- and hardware can cope with a wide variety of formats. Theoretically, magnification of a round spot to a total filling of the screen (resolution $512 \times 512$ ) would give a maximum of approx. 200000 pixels per spot. Considering the carbon spot diameter (i.e., $1.5 \mathrm{~mm}$ ) this would be analogous to one pixel covering a square of 3 $\times 3 \mu \mathrm{m}$. These figures are comparable to those obtained with other equipment such as laser scanning densitometry.

By using particular filters, computer image analysis can be applied to other SPIA labels with different colors as well. In principle, the right filter in combination with optimized lighting will give the opportunity to measure the same range of intensity (i.e., 0 to 255). In this way, computer image analysis will be useful as a universal, quantitative test method in many (diagnostic) fields. It can be concluded that colloidal carbon particles are useful and widely applicable as label in rapid immunochemical test methods. Data-recording and -processing of the carbon spots by computer image analysis is feasible. Studies on optimization for sensitivity, assessment of accuracy and precision and lowest detectable concentrations are in progress. Another SPIA that is presently being developed is a rapid dipstick device to measure human choriogonadotropin. With this SIPIA $5 \mathrm{mIU}$ of choriogonadotropin per $\mathrm{ml}$ can be detected in less than $5 \mathrm{~min}$, both by computer image analysis and by visual examination. The manuscript describing these experiments is in preparation. 


\section{Acknowledgement}

The authors greatly acknowledge the contributions of M.M.T. Meijer, W.T.J. Spekking and R.M.P.J. Willems.

\section{References}

Gosling, J.P. (1990) A decade of development in immunoassay methodology. Clin. Chem. 36(8), $1408-1427$.

Hogan, M.M., Perera, P.Y. and Vogel, S.N. (1989) Examination of macrophage cell surface antigen regulation by rIFN-gamma and IFN-alpha/beta utilizing digital imaging by a novel laser detection system. Anchored cell analysis station (ACAS) 470. J. Immunol. Meth. 123, 9-18.

McClelland, R.A., Wilson, D., Leake, R., Finlay, P. and Nicholson R.I. (1991) A multicentre study into the reliability of steroid receptor immunocytochemical assay quantification. Eur. J. Cancer 27, $711-715$.

Palfreyman, J.W., Vigrow, A., Button, D. and Glancy, H. (1988) Simple method for scanning immunoblots. J. Immunol. Meth. 109, 199-201.

Prather, T.L., Grande, J., Keese, C.R. and Giaever, I. (1986) An agglutination assay using emulsified oils. J. Immunol. Meth. 87, 211-215.

Salgaller, M., Agius, L., Yates, A., Pearl, D., Roberts, W. and Stephens, R. (1990) Application of automated image analysis to demonstrate the correlation between ras p21 expression and severity of gliomas. Biochem. Biophys. Res. Commun. 169, 482-491.

Sondergaard, I., Poulsen, L.K., Hagerup, M. and Conradsen, K. (1987) Image processing and pattern recognition algorithms for evaluation of crossed immunoelectrophoretic patterns (crossed radioimmunoelectrophoresis analysis manager; CREAM). Anal. Biochem. 165, 384-391.

Stemerman, D., Papadea, C., Martino-Saltzman, D., O'Connell, C., Demaline, B. and Austin, G.E. (1989) Precision and reliability of paraprotein determination by high-resolution agarose gel electrophoresis. Am. J. Clin. Pathol. 91, 435-440.

Ungar, B.L.P. and Nash, T.E. (1986) Quantification of specific antibody response to Cryptosporidium antigens by laser densitometry. Infect. Immun. 53, 124-128.

Van Doorn, A.W.J., Wichers, J.H. and Van Gelder, W.M.J. (1988) A method of determining in a testsample one or more components of the reaction between a specifically-binding protein and the corresponding bindable substance using at least one labelled component, a method of preparing the labelled component, and a testkit for the determination of immuno components. European Patent Application, EP.A 88202597.6.

Wichers, J.H., Van Gelder, W.M.J. and Van Doorn, A.W.J. (1989a) Process for the preparation of elemental sols. European Patent Application, EP.A 89202882.0.

Wichers, J.H., Van Es, R.M., Keizer, G.D., Van Doorn, A.W.J. and Van Gelder, W.M.J. (1989b) Process for the preparation of sols. European Patent Application, EP.A 89202883.8. 